\title{
Subclinical left ventricular dysfunction in COVID-19 recovered patients using speckle tracking echocardiography
}

\author{
Sudhanshu Mahajan ${ }^{1}$, Shekhar Kunal ${ }^{1}$, Bhushan Shah ${ }^{1}$, Shobhit Garg ${ }^{2}$, Girish MP ${ }^{1}$, Ankit \\ Bansal $^{1}$, Vishal Batra ${ }^{1}$, Jamal Yusuf ${ }^{1}$, Saibal Mukhopadhyay ${ }^{1}$, Suresh Kumar ${ }^{2}$, Sanjay \\ Tyagi ${ }^{1}$, Anubha Gupta ${ }^{3}$, and Mohit Gupta ${ }^{1}$ \\ ${ }^{1}$ GB Pant Hospital \\ ${ }^{2}$ Maulana Azad Medical College \\ ${ }^{3}$ Indraprastha Institute of Information Technology Delhi
}

June 1, 2021

\begin{abstract}
Objectives: Myocardial injury during active coronavirus disease-2019 (COVID-19) infection is well described however, its persistence during recovery is unclear. We assessed left ventricle (LV) global longitudinal strain (GLS) using speckle tracking echocardiography (STE) in COVID-19 recovered patients and studied its correlation with various parameters. Methods: A total of 134 subjects within 30-45 days post recovery from COVID-19 infection and normal LV ejection fraction were enrolled. Routine blood investigations, inflammatory markers (on admission) and comprehensive echocardiography including STE were done for all. Results: Of the 134 subjects, 121 (90.3\%) were symptomatic during COVID-19 illness and were categorized as mild: 61 (45.5\%), moderate: 50 (37.3\%) and severe: 10 (7.5\%) COVID-19 illness. Asymptomatic COVID-19 infection was reported in $13(9.7 \%)$ patients. Subclinical LV and right ventricle (RV) dysfunction were seen in $40(29.9 \%)$ and $14(10.5 \%)$ patients respectively. Impaired LVGLS was reported in 1 (7.7\%), 8 (13.1\%), $22(44 \%)$ and $9(90 \%)$ subjects with asymptomatic, mild, moderate and severe disease respectively. LVGLS was significantly lower in patients recovered from severe illness (mild: -21 $\pm 3.4 \%$; moderate: $-18.1 \pm 6.9 \%$; severe: $-15.5 \pm 3.1 \%$; $\mathrm{P}<0.0001)$. Subjects with reduced LVGLS had significantly higher interleukin-6 $(\mathrm{P}<0.0001)$, C-reactive protein $(\mathrm{P}=0.001)$, lactate dehydrogenase $(\mathrm{P}=0.009)$ and serum ferritin $(\mathrm{P}=0.03)$ levels during index admission. Conclusions: Subclinical LV dysfunction was seen in nearly a third of recovered COVID-19 patients while $10.5 \%$ had RV dysfunction. Our study suggests a need for closer follow-up among COVID-19 recovered subjects to elucidate long-term cardiovascular outcomes.
\end{abstract}

\section{Introduction:}

The ongoing coronavirus disease-2019 (COVID-19) pandemic continues to cause considerable morbidity and mortality worldwide. ${ }^{1}$ Cardiovascular manifestations in COVID-19 include myocarditis, acute coronary syndrome, cardiac arrhythmias, heart failure, cardiogenic shock and venous thromboembolism. ${ }^{2,3}$ Acute cardiac injury (defined by elevated cardiac troponin levels) has been reported in 8-28\% of patients with COVID19 and is associated with worse clinical outcomes. ${ }^{24-6}$ In addition, few studies have observed subclinical myocardial dysfunction in COVID-19 patients. ${ }^{7,8}$ However, there is paucity of data regarding myocardial dysfunction in COVID-19 recovered patients.

Initial studies using cardiac magnetic resonance (CMR) imaging have shown relatively high prevalence of subclinical left ventricle (LV) dysfunction in recovered COVID-19 patients. ${ }^{9-11}$ Despite being the "gold standard" CMR is often limited by its availability, longer imaging time and feasibility especially in light of ongoing pandemic. Hence, there is an urgent need for a systematic study to identify the prevalence of subclinical myocardial dysfunction using simple bedside tools. Global longitudinal strain (GLS) obtained by two-dimensional 
speckle tracking echocardiography (STE) is a sensitive and validated method for detection of subclinical LV dysfunction compared with ejection fraction $(\mathrm{EF}) .{ }^{12}$ In the present study, we assessed LVGLS in recovered COVID-19 patients and its correlation with various laboratory parameters and inflammatory markers.

\section{Methods:}

This was a prospective single centre study in a tertiary care centre of North India from August 2020 to March 2021. A total of 527 consecutive subjects recently recovered (within 30-45 days) from COVID-19 infection were screened. All these subjects were COVID-19 positive in the past using reverse transcription-polymerase chain reaction (RT-PCR) swab test. Patients were considered recovered by the discharge criteria (normal temperature lasting longer than 3 days, resolved respiratory symptoms and two consecutive negative RT-PCR test results separated by at least 24 hours) and were isolated for a minimum of 14 days. Subjects with age greater than 85 years $(\mathrm{n}=28)$, pre-existing cardiovascular disease [coronary artery disease $(\mathrm{n}=55)$, dilated $(\mathrm{n}=16)$, restrictive $(\mathrm{n}=1)$ and hypertrophic cardiomyopathies $(\mathrm{n}=1)]$, uncontrolled hypertension [(stage 2 or more); $\mathrm{n}=52$ ], uncontrolled diabetes mellitus [(HbA1c [?] 8); $\mathrm{n}=70$ ], prior cerebrovascular disease $(\mathrm{n}=31)$, chronic liver $(\mathrm{n}=15)$ or kidney disease [(eGFR $<30 \mathrm{ml} / \mathrm{min} / \mathrm{m} 2) ; \mathrm{n}=20$ ], chronic obstructive pulmonary disease $(\mathrm{n}=46)$ and poor echo window $(\mathrm{n}=42)$ were excluded as these are known to impair LV strain analysis. ${ }^{13}$ In addition, patients with impaired LV function $(\mathrm{n}=16)$ on baseline transthoracic echocardiography (TTE) were also excluded. Post exclusion, 134 subjects were finally enrolled and underwent sequential testing (Figure 1, Central illustration ). Baseline clinical and biochemical parameters including hemogram, liver and kidney function tests as well as inflammatory markers such as C-reactive protein (CRP), serum ferritin, interleukin (IL)-6, lactate dehydrogenase (LDH) and D-dimer were obtained at the time of admission during COVID-19 infection for all subjects.

A TTE (Philips EPIQ 7, USA) was performed and all baseline echocardiographic parameters such as LV end diastolic dimension (LVEDd), LV end systolic dimension (LVESd), left atrial (LA) size, LVEF (modified Simpson's method) and LV diastolic function were recorded as per the American Society of Echocardiography (ASE) guidelines. ${ }^{14-16}$ LVGLS was determined using two dimensional-STE. Three standard apical views (apical two chamber (A2C), apical three chamber (A3C), apical four chamber (A4C) views) were obtained at rest and for each of these views, well-defined cardiac cycles were acquired and stored for offline analysis using the Automated Cardiac Motion Quantification (aCMQ) feature on the Qlab software (QLab Cardiac Analysis ver.10, Philips Healthcare Inc). The mean GLS was calculated by averaging the peak GLS values of the three apical views. A 17-segment polar plot (Bulls' eye) provided visual and quantitative representations of regional LV functions by plotting color-coded values of peak-systolic strain. ${ }^{17}$ A LVGLS value of $<-$ 18.9 was considered abnormal. ${ }^{18}$ In addition, right ventricular (RV) systolic function was assessed using (a) Tricuspid annular plane systolic excursion (TAPSE), (b) Tissue Doppler systolic velocity of the tricuspid annulus ( $\left.\mathrm{S}^{\prime}\right)$ and complimented by assessment of RV basal diameter. Echocardiogram and interpretation of strain imaging was done by two independent reviewers who were blinded to the study data. The study was approved by the Institutional ethics committee (F.1/IEC/MAMC/(82/10/2020/No.77) and a written informed consent was obtained from each patient prior to enrollment.

\section{Statistical Analysis:}

Continuous data was expressed as mean \pm standard deviation (SD) and categorical data was represented as proportions. Normality of distribution of continuous variables were assessed using the Kolmogorov-Smirnov test. Comparison of means of continuous variables was done using Student's t-test or Mann-Whitney U test as appropriate while Fisher exact test or $\chi^{2}$ test was used for categorical variables. In addition, analysis of variance (ANOVA) or Kruskal Wallis with post-hoc analysis was used to compare mean values of continuous variables between the three groups based on severity of COVID-19. Correlation between inflammatory markers and LVGLS was done using Spearman correlation coefficient test. Multivariate logistic regression analysis was done to determine factors independently associated with reduced GLS. To investigate for interobserver variability for LVGLS, analysis of 20 random subjects was done by two independent investigators who were blinded to the clinical data. For intra-observer variability, repeat offline LVGLS estimation was done ten days later in 20 randomly selected patients. The interclass correlation coefficients (ICCs) were calculated 
with point estimates and $95 \%$ confidence intervals (CIs) being reported. A two-sided $\mathrm{P}$ value of $<0.05$ was considered to be statistically significant. SPSS version 24.0 (IBM Corp, Armonk, NY) and GraphPad Prism version 8.0.0 (GraphPad Software, San Diego, CA) software were used for statistical analysis.

\section{Results:}

The baseline demographic characteristics of 134 subjects is depicted inTable $\mathbf{1}$. The mean age of the enrolled patients was $51.2 \pm 12.4$ years with $85(63.4 \%)$ of them being males. Co-morbidities such as hypertension and diabetes mellitus were reported in $37(27.6 \%)$ and $23(17.2 \%)$ subjects respectively. A total of $121(90.3 \%)$ subjects reported symptoms during COVID-19 infection. Symptomatic patients were classified into mild [n $=61(45.5 \%)]$, moderate $[\mathrm{n}=50(37.3 \%)]$ or severe $[\mathrm{n}=10(7.5 \%)]$ illness as per the National Institute of Health (NIH) severity criteria. ${ }^{19}$ During the active COVID-19 infection, fever, cough and dyspnea were the predominant symptoms observed in 95 (70.8\%), 73 (54.4\%) and 51 (38.1\%) patients respectively. During the post COVID-19 recovery phase, $62(46.2 \%)$ patients were symptomatic with palpitations, dyspnea and fatigue being the predominant symptoms reported in 29 (21.6\%), 23 (17.2\%), 18 (13.4\%) subjects respectively. The mean duration for follow-up echocardiogram post COVID-19 recovery was $36.4+4.6$ days.

Echocardiographic profile of COVID-19 recovered subjects is depicted inSupplementary Table S1 . Mitral regurgitation was present in $12(8.9 \%)$ subjects while tricuspid regurgitation was reported in $27(20.1 \%)$ subjects. Diastolic dysfunction was reported in $38(28.3 \%)$ subjects of whom $32(23.8 \%)$ had grade I, 5 $(3.7 \%)$ had grade II and $1(0.7 \%)$ had grade III diastolic dysfunction. Right ventricle systolic pressure (RVSP) was raised in $5(3.7 \%)$ subjects while RV dysfunction (defined as TAPSE $<17 \mathrm{~mm}$ and RV S' velocity $<9.5 \mathrm{~cm} / \mathrm{s})$ was observed in $14(10.4 \%)$ subjects. The mean LVGLS for entire study cohort was $-19.7 \pm 4.6 \%$ with impaired LVGLS $(<-18.9 \%)$ in $40(29.9 \%)$ subjects.

\section{Echocardiographic parameters based on severity of COVID-19 illness:}

There was no significant difference in the prevalence of hypertension and diabetes mellitus between the three groups. Patients in severe COVID-19 illness group had significantly higher levels of inflammatory markers such as CRP $(\mathrm{P}=0.006)$ and IL-6 $(\mathrm{P}=0.002)$, total leucocyte count $(\mathrm{P}=0.003)$ and lower hemoglobin levels $(\mathrm{P}=0.004)$ as compared to those with mild disease. There was no significant difference with respect to conventional echocardiographic parameters (such as LVEF, LVEDd, LVESd, LA size) and diastolic dysfunction among the three groups. Of the 13 asymptomatic patients, reduced LVGLS was observed in only one $(7.7 \%)$ patient. A significant difference was noted between mean LVGLS values between asymptomatic $(-21.8 \pm 3.3 \%)$ and symptomatic $(-19.5 \pm 4.6 \%)$ subjects $(\mathrm{P}=0.03)$. Among symptomatic patients, there was a significant difference of mean LVGLS values among the three groups (mild: $-21 \pm 3.4 \%$; moderate: $-18.1+-6.9 \%$; severe: $-15.5+-3.1 \% ; \mathrm{P}<0.0001)$ as depicted in Table $\mathbf{2}$. The ICC for LVGLS measurement was 0.95 [95\% CI: 0.84-0.98] for inter-observer agreement and 0.97 (95\% CI: 0.94-0.99) for intra-observer agreement, indicating good inter-observer and intra-observer correlations. Representative bull's eye plot of LVGLS in mild (A), moderate (B) and severe (C) COVID-19 subjects is illustrated in Figure 2 .

\section{Correlation of LVGLS with inflammatory markers:}

Levels of inflammatory markers during active COVID-19 infection correlated significantly with LVGLS post COVID-19 recovery (IL-6 levels $(\mathrm{r}=0.51 ; \mathrm{P}<0.0001)$, CRP levels $(\mathrm{r}=0.39 ; \mathrm{P}=0.001)$, LDH $(\mathrm{r}=0.27$; $\mathrm{P}=0.02)$ and serum ferritin levels $(\mathrm{r}=0.25 ; \mathrm{P}=0.03)$ as demonstrated in Figure 3 .

\section{Predictors of reduced strain in COVID-19 recovered subjects:}

A longer duration of hospital stay (greater in severe COVID-19 infection) and male sex were the important predictors of reduced strain (Table 3 ). Age and co-morbidities such as hypertension and diabetes mellitus had no impact on LVGLS in post COVID-19 recovered subjects. Of note, in subjects with reduced LVGLS had significantly higher levels of inflammatory markers such as IL-6 $(\mathrm{P}<0.0001)$ and CRP $(\mathrm{P}=0.001)$ levels along with raised serum LDH $(\mathrm{P}=0.009)$ and serum ferritin $(\mathrm{P}=0.03)$ during active COVID-19 infection (Table 3 ). Additionally, these subjects were more likely to have a lower TAPSE and a higher RV basal diameter. No significant difference was observed between the groups with respect to other echocardiographic 
parameters (LVEF, LVEDd, LVESd, LA size, RVSP and diastolic dysfunction). On Multivariate logistic regression, severity of COVID-19 illness was the only independent predictor of reduced LVGLS in COVID-19 recovered subjects (odds ratio $(\mathrm{OR}): 4.47 ; 95 \% \mathrm{CI}: 1.1-18.9 ; \mathrm{P}=0.04)($ Figure 4 ).

\section{Discussion:}

The present study evaluated the presence of subclinical myocardial dysfunction using two-dimensional strain analysis via STE in COVID-19 recovered subjects. The major finding of our study was the presence of subclinical LV dysfunction in $40(29.9 \%)$ patients who had recovered from COVID-19. Impaired LV strain post COVID-19 recovery was seen in 1 (7.7\%) 8 (13.1\%), 22 (44\%) and $9(90 \%)$ subjects respectively in asymptomatic, mild, moderate and severe COVID-19 illness groups (Figure 1, Central illustration ). It is noteworthy that even patients with mild to moderate disease had residual subclinical LV dysfunction during the recovery period. These findings are important as subclinical cardiac involvement is not well elucidated and is often overlooked in patients who have recovered from COVID-19.

Cardiac involvement in COVID-19 is often multifactorial with (a) systemic inflammatory response due to cytokine storm, (b) hypoxia induced oxygen supply-demand mismatch, (c) micro-or macrovascular thrombosis following inflammation and endothelial dysfunction and (d) direct myocardial injury due to viral cytopathic effect being the postulated mechanisms. ${ }^{3}$ In addition, there has been evidence of subclinical LV dysfunction in COVID-19 recovered patients due to persistent cardiac inflammation in the form of peri-myocarditis and early myocardial fibrosis. ${ }^{10,11}$ LVGLS determination using STE is an objective and reproducible technique for evaluation of myocardial deformation. ${ }^{20}$ LVGLS serves as a more sensitive and earlier predictor of LV systolic dysfunction as compared to LVEF. ${ }^{21}$ Additionally, it has been also shown to predict subclinical myocardial dysfunction because of its ability to detect myocardial fibrosis early in the disease process. ${ }^{20}$ Initial studies have shown the utility of LVGLS in predicting cardiac involvement in in patients with active COVID-19 infection. ${ }^{8,22,23}$ There is a limited evidence regarding the role of LVGLS in COVID-19 recovered patients. In a small study from Turkey, LVGLS was impaired in 28 (37.8\%) patients one-month post discharge following COVID-19 infection. ${ }^{24}$ In our study, nearly one-third of the patients (29.9\%) had a reduced LVGLS following recovery from COVID-19.

These findings have also been substantiated on CMR imaging wherein subclinical functional and myocardial tissue characteristic abnormalities have been detected in individuals post COVID-19 infection. A small study of 26 COVID-19 recovered patients reported myocardial edema in $14(54 \%)$ patients and late gadolinium enhancement in $8(31 \%)$ patients. ${ }^{9}$ However, they included patients recovering from moderate or severe COVID-19 illness. Another study of 100 recovered patients (majority with moderate and severe disease) found ongoing myocardial inflammation in 60 patients $[60 \%] .{ }^{10}$ This study included significant number of patients with various comorbidities like diabetes mellitus, hypertension, coronary artery disease that could have contributed to the ongoing inflammation. Though CMR imaging is the "gold standard" to detect subclinical myocardial involvement, its accessibility and affordability in low-medium income countries is a major concern. Additionally, given the huge burden of COVID-19 recovered patients, it is practically impossible to follow-up all patients with CMR. In such situations, two-dimensional strain imaging is a simple, cost-effective and easily available tool to detect subclinical myocardial dysfunction in these patients.

In present study, mean LVGLS values (post recovery) among mild, moderate and severe COVID-19 illness groups were $-21+-3.4 \%,-18.1+-6.9 \%$ and $-15.5+-3.1 \%$ respectively which implies that patient with severe COVID-19 infection had a higher residual LV dysfunction as compared to those with mild/moderate disease. Similar patterns have been observed during active COVID-19 infection where patients with severe disease had marked reduction in LVGLS. ${ }^{8}$ In our study, patients in the severe COVID-19 group had significantly higher levels of inflammatory markers and lower hemoglobin levels. This was consistent with findings from previous studies as well as a metanalysis. ${ }^{25}$ Additionally, it was also seen that patients with higher levels of inflammatory markers during active COVID-19 infection had a greater reduction in LVGLS post recovery from COVID-19. Similar correlation has been demonstrated in a previous study between CRP levels and post COVID-19 recovery LVGLS $[\mathrm{r}=0.39, \mathrm{P}<0.001] .{ }^{24}$ Apart from subclinical LV dysfunction, RV dysfunction was documented in 14 (10.5\%) subjects in our study. Patients with reduced LVGLS had significantly higher 
RV basal diameter and lower TAPSE. Previous studies have evaluated RV function in patients with active COVID-19 infection and reported higher RV basal diameter or RV dilatation in approximately one third of patients. ${ }^{8,26,27}$

The clinical significance of abnormal LVGLS in COVID-19 recovered patients is still unclear however, it does merit further investigation. Future studies in unselected COVID-19 recovered patients are needed to understand the natural progression of persistent myocardial damage and subclinical LV dysfunction. It will be of interest to see whether abnormal strain in recovered patients is an adverse prognostic marker. It was a single center study with a relatively small sample size. One of the inherent limitations of STE is the large number of clinical conditions and imaging quality which can impact the LVGLS. Hence, subjects with these confounding clinical conditions were excluded and STE was performed in a select subset of COVID19 recovered patients. One of the other limitations possibly could be a lack of baseline echocardiography during the active COVID-19 infection due to the logistic issues in resource limited countries such as ours in the initial phases of the pandemic. Additionally, there was a lack of use of CMR imaging and absence of long-term follow up. However, we do plan to follow-up these subjects and sequentially assess their strain pattern.

\section{Conclusion:}

The present study provides important insights into the prevalence of subclinical myocardial dysfunction in recovered COVID-19 subset. Nearly a third of patients recovering from COVID-19 had subclinical LV dysfunction while $10.5 \%$ of them had RV dysfunction. The presence of such persistent myocardial dysfunction in recovered subjects suggests cardiac involvement as a possible lasting consequence of COVID-19. This study reiterates the importance of STE as a practical imaging modality for detection of subclinical myocardial dysfunction especially amidst the huge burden of recovered patients. It also highlights the need for long term follow-up of these subjects to unmask long-term cardiovascular consequences of COVID-19 infection.

\section{Acknowledgments: None}

Author contributions: SK, MDG, SM and JY had conceptualized and designed the study. Data collection was performed by SM, SK, BS, SG and SK. Statistical analysis was done by SK and AG. Analysis/interpretation of the data was done by SK, VB, JY, SM and AG. Drafting of the article was done by SM, SG, SK, GMP, JY, ST, SK, AG and AB. Critical revision of article was done by BS, MDG, VB, SM. Article was approved by SM, SG, SK, GMP, JY, ST, SK, AG, AB, BS, MDG, VB, SM.

\section{References:}

1. Zhou P, Yang XL, Wang XG, et al. A pneumonia outbreak associated with a new coronavirus of probable bat origin. Nature. 2020; 579: 270-3.

2. Shi S, Qin M, Shen B, et al. Association of cardiac injury with mortality in hospitalized patients with COVID-19 in Wuhan, China. JAMA Cardiol. 2020; 5: 802-10.

3. Nishiga M, Wang DW, Han Y, et al. COVID-19 and cardiovascular disease: from basic mechanisms to clinical perspectives. Nat Rev Cardiol. 2020; 17: 543-58.

4. Chapman AR, Bularga A, Mills NL. High-sensitivity cardiac troponin can be an ally in the fight against COVID-19. Circulation. 2020; 141: 1733-5.

5. Zhou F, Yu T, Du R, et al. Clinical course and risk factors for mortality of adult inpatients with COVID-19 in Wuhan, China: a retrospective cohort study. Lancet. 2020; 395: 1054-62.

6. Kunal S, Sharma SM, Sharma SK, et al. Cardiovascular complications and its impact on outcomes in COVID-19. Indian Heart J. 2020; 72: 593-8.

7. Huang C, Wang Y, Li X, et al. Clinical features of patients infected with 2019 novel coronavirus in Wuhan, China. Lancet. 2020; 395: 497-506.

8. Baycan OF, Barman HA, Atici A, et al. Evaluation of biventricular function in patients with COVID-19 using speckle tracking echocardiography. Int J Cardiovasc Imaging. 2021; 37: 135-44.

9. Huang L, Zhao P, Tang D, et al. Cardiac involvement in patients recovered from COVID-2019 identified using Magnetic Resonance Imaging. J Am Coll Cardiol Img. 2020; 13: 2330-9. 
10. Puntmann VO, Carerj ML, Wieters I, et al. Outcomes of Cardiovascular Magnetic Resonance Imaging in patients recently recovered from coronavirus disease 2019 (COVID-19). JAMA Cardiol. 2020; 5: 1265-73.

11. Wang H, Li R, Zhou Z, et al. Cardiac involvement in COVID-19 patients: mid-term follow up by cardiovascular magnetic resonance. J Cardiovasc Magn Reson. 2021; 23:14.

12. Wibowo A, Pranata R, Astuti A, et al. Left and right ventricular longitudinal strains are associated with poor outcome in COVID-19: a systematic review and meta-analysis. J Intensive Care. 2021; 9: 9.

13. Soufi Taleb Bendiab N, Meziane-Tani A, Ouabdesselam S, et al. Factors associated with global longitudinal strain decline in hypertensive patients with normal left ventricular ejection fraction. Eur J Prev Cardiol. 2017; 24: 1463-72.

14. Potter E, Marwick TH. Assessment of left ventricular function by echocardiography: The case for routinely adding Global Longitudinal Strain to ejection fraction. J Am Coll Cardiol Img. 2018; 11: 260-74.

15. Lang RM, Badano LP, Mor-Avi V, et al. Recommendations for cardiac chamber quantification by echocardiography in adults: an update from the American Society of Echocardiography and the European Association of Cardiovascular Imaging. J Am Soc Echocardiogr. 2015; 28: 1-39.

16. Nagueh SF, Smiseth OA, Appleton CP, et al. Recommendations for the evaluation of Left Ventricular Diastolic Function by Echocardiography: An Update from the American Society of Echocardiography and the European Association of Cardiovascular Imaging. J Am Soc Echocardiogr. 2016; 29: 277-314.

17. Voigt JU, Pedrizzetti G, Lysyansky P, et al. Definitions for a common standard for 2D speckle tracking echocardiography: consensus document of the EACVI/ASE/Industry Task Force to standardize deformation imaging. J Am Soc Echocardiogr. 2015; 28: 183-93.

18. Takigiku K, Takeuchi M, Izumi C, et al. JUSTICE investigators. Normal range of left ventricular 2-dimensional strain: Japanese Ultrasound Speckle Tracking of the Left Ventricle (JUSTICE) study. Circ J. 2012; 76: 2623-32.

19. COVID-19 Treatment Guidelines Panel. Coronavirus Disease 2019 (COVID-19) Treatment Guidelines. National Institutes of Health. Available at https://www.covid19treatmentguidelines.nih.gov/. Accessed on April 13, 2021

20. Kostakou PM, Kostopoulos VS, Tryfou ES, et al. Subclinical left ventricular dysfunction and correlation with regional strain analysis in myocarditis with normal ejection fraction. A new diagnostic criterion. Int J Cardiol. 2018; 259: 116-21.

21. Collier P, Phelan D, Klein A. A Test in Context: Myocardial strain measured by Speckle-Tracking Echocardiography. J Am Coll Cardiol. 2017; 69: 1043-56.

22. Croft LB, Krishnamoorthy P, Ro R, et al. Abnormal left ventricular global longitudinal strain by speckle tracking echocardiography in COVID-19 patients. Future Cardiol. 2020:10.2217/fca-20200121.

23. Bhatia HS, Bui QM, King K, et al. Subclinical left ventricular dysfunction in COVID-19. Int J Cardiol Heart Vasc. 2021; 34:100770.

24. Ozer S, Candan L, Ozylldız AG, et al. Evaluation of left ventricular global functions with speckle tracking echocardiography in patients recovered from COVID-19. Int J Cardiovasc Imaging. 2021:1-7.

25. Kermali M, Khalsa RK, Pillai K, et al. The role of biomarkers in diagnosis of COVID-19 - A systematic review. Life Sci. 2020; 254: 117788.

26. Li Y, Li H, Zhu S, et al. Prognostic value of right ventricular longitudinal strain in patients with COVID-19. J Am Coll Cardiol Img. 2020; 13: 2287-99.

27. Argulian E, Sud K, Vogel B, et al. Right ventricular dilation in hospitalized patients with COVID-19 Infection. J Am Coll Cardiol Img. 2020; 13: 2459-61.

Table 1: Demographic and baseline clinical profile of study subjects

Baseline parameters

Age (years) 
Baseline parameters

Male sex

Comorbidities Hypertension Diabetes mellitus

Smoking

Duration of hospitalization (days)

Heart Rate (per minute)

Systolic blood pressure ( $\mathrm{mm} \mathrm{Hg}$ )

Diastolic blood pressure ( $\mathrm{mm} \mathrm{Hg}$ )

Symptoms on admission Fever Cough Dyspnoea Sore throat Myalgias Chest pain Fatigue Loss of smell Palpitation Loss

Post COVID-19 recovery symptoms Palpitations Dyspnoea Fatigue Cough Syncope Pedal oedema Fever

Severity of COVID-19 illness Asymptomatic Mild Moderate Severe

Table 2: Comparison of demographic, biochemical and echocardiographic parameters according to severity of COVID-19 illness

\begin{tabular}{|c|c|c|c|c|c|c|c|}
\hline Parameters & $\begin{array}{l}\text { Group } 1(\mathrm{n} \\
=61)\end{array}$ & $\begin{array}{l}\text { Group } 2(\mathrm{n} \\
=50)\end{array}$ & $\begin{array}{l}\text { Group } 3(\mathrm{n} \\
=10)\end{array}$ & P-value & $\begin{array}{l}\text { Group } 1 \text { vs } \\
2\end{array}$ & $\begin{array}{l}\text { Group } 1 \text { vs } \\
3\end{array}$ & $\begin{array}{l}\text { Group } 2 \text { vs } \\
3\end{array}$ \\
\hline $\begin{array}{l}\text { Age } \\
\text { (years) }\end{array}$ & $\begin{array}{l}52.4 \pm \\
12.5\end{array}$ & $\begin{array}{l}50.7 \pm \\
11.5\end{array}$ & $\begin{array}{l}44.0 \pm \\
15.8\end{array}$ & 0.14 & 0.75 & 0.12 & 0.26 \\
\hline Male sex & $32(52.4 \%)$ & $40(80 \%)$ & $8(80 \%)$ & 0.006 & & & \\
\hline \multicolumn{2}{|c|}{ Comorbidities6 (9.8\%) } & $13(26 \%)$ & $2(20 \%) 3$ & 0.080 .06 & & & \\
\hline $\begin{array}{l}\text { Diabetes } \\
\text { mellitus }\end{array}$ & $11(18 \%)$ & $19(38 \%)$ & $(30 \%)$ & & & & \\
\hline \multicolumn{8}{|l|}{ Hypertension } \\
\hline Smoking & $2(3.2 \%)$ & $3(6 \%)$ & $0(0 \%)$ & 0.61 & & & \\
\hline $\begin{array}{l}\text { Duration } \\
\text { of hospi- } \\
\text { talization } \\
\text { (days) }\end{array}$ & $\begin{array}{l}6.84 \pm \\
6.64\end{array}$ & $9.8 \pm 5.8$ & $\begin{array}{l}17.3 \pm \\
12.5\end{array}$ & 0.003 & 0.007 & 0.008 & 0.251 \\
\hline $\begin{array}{l}\text { Heart } \\
\text { Rate (per } \\
\text { minute) }\end{array}$ & $82.1 \pm 9.6$ & $\begin{array}{l}80.6 \pm \\
11.2\end{array}$ & $83.4 \pm 8.6$ & 0.75 & 0.89 & 0.98 & 0.84 \\
\hline $\begin{array}{l}\text { Systolic } \\
\text { blood } \\
\text { pressure } \\
(\mathrm{mm} \mathrm{Hg})\end{array}$ & $\begin{array}{l}133.6 \pm \\
14.4\end{array}$ & $\begin{array}{l}133.2 \pm \\
14.4\end{array}$ & $\begin{array}{l}132.3 \pm \\
9.7\end{array}$ & 0.69 & 0.99 & 0.99 & 0.99 \\
\hline $\begin{array}{l}\text { Diastolic } \\
\text { blood } \\
\text { pressure } \\
\text { (mm Hg) }\end{array}$ & $82.2 \pm 7.8$ & $81.5 \pm 7.4$ & $83.7 \pm 5.8$ & 0.16 & 0.96 & 0.93 & 0.83 \\
\hline
\end{tabular}




\begin{tabular}{|c|c|c|c|c|c|c|c|}
\hline Parameters & $\begin{array}{l}\text { Group } 1(\mathrm{n} \\
=61)\end{array}$ & $\begin{array}{l}\text { Group } 2(\mathrm{n} \\
=50)\end{array}$ & $\begin{array}{l}\text { Group } 3(\mathbf{n} \\
=10)\end{array}$ & P-value & $\begin{array}{l}\text { Group } 1 \mathrm{vs} \\
2\end{array}$ & $\begin{array}{l}\text { Group } 1 \text { vs } \\
3\end{array}$ & $\begin{array}{l}\text { Group } 2 \text { vs } \\
3\end{array}$ \\
\hline $\begin{array}{l}\text { Laboratory } \\
\text { parame- } \\
\text { ters } \\
\text { Haemoglobin } \\
(\mathrm{gm} \%) \\
\mathrm{TLC} \text { (per } \\
\left.\mathrm{mm}^{3}\right) \\
\text { Platelet } \\
\text { count } \\
\left(* 10^{5} / \mathrm{mL}\right) \\
\text { Serum } \\
\text { creatinine } \\
(\mathrm{mg} / \mathrm{dl}) \\
\mathrm{D}-\mathrm{dimer} \\
(\mu \mathrm{L} / \mathrm{L})\end{array}$ & $\begin{array}{l}13.5 \pm \\
1.31 \\
9434.8 \pm \\
10825.4 \\
2.51 \pm \\
0.981 .10 \\
\pm 1.5 \\
407.2 \pm \\
322.3\end{array}$ & $\begin{array}{l}12.8 \pm 1.8 \\
10309.4 \pm \\
15344.1 \\
2.40 \pm \\
1.320 .92 \\
\pm 0.5 \\
652.5 \pm \\
1079.7\end{array}$ & $\begin{array}{l}11.6 \pm \\
1.80 \\
11334.2 \pm \\
2073.1 \\
2.77 \pm \\
1.020 .99 \\
\pm 0.5 \\
934.7 \pm \\
1420.8\end{array}$ & $\begin{array}{l}\mathbf{0 . 0 0 1} \\
\mathbf{0 . 0 0 8} \\
0.2150 .75 \\
0.628\end{array}$ & $\begin{array}{l}\mathbf{0 . 0 0 2} \\
0.996 \\
0.8660 .72 \\
0.53\end{array}$ & $\begin{array}{l}\mathbf{0 . 0 0 4} \\
\mathbf{0 . 0 0 3} \\
0.8530 .95 \\
0.30\end{array}$ & $\begin{array}{l}0.298 \\
\mathbf{0 . 0 0 3} \\
0.6820 .98 \\
0.70\end{array}$ \\
\hline $\begin{array}{l}\text { Inflammator } \\
\text { markers } \\
\mathrm{CRP} \\
(\mathrm{mg} / \mathrm{L}) \\
\mathrm{IL}-6 \\
(\mathrm{pg} / \mathrm{ml}) \\
\mathrm{LDH} \\
(\mathrm{U} / \mathrm{L}) \\
\text { Ferritin } \\
(\mu \mathrm{g} / \mathrm{L})\end{array}$ & $\begin{array}{l}y 12.84 \pm \\
30.16 .64 \\
\pm 14.5 \\
358.6 \pm \\
168.5 \\
333.4 \pm \\
277.5\end{array}$ & $\begin{array}{l}37.7 \pm \\
100.228 .2 \\
\pm 64.8 \\
473.2 \pm \\
379.6 \\
323.1 \pm \\
154.5\end{array}$ & $\begin{array}{l}606.5 \pm \\
1373.2 \\
115.9 \pm \\
139.3 \\
576.6 \pm \\
238.9 \\
629.7 \pm \\
553.9\end{array}$ & $\begin{array}{l}\mathbf{0 . 0 1} \\
\mathbf{0 . 0 0 1} \\
0.103 \\
0.116\end{array}$ & $\begin{array}{l}0.045 \\
\mathbf{0 . 0 0 2} \\
0.270 .53\end{array}$ & $\begin{array}{l}\mathbf{0 . 0 0 6} \\
\mathbf{0 . 0 0 2} \\
0.270 .99\end{array}$ & $\begin{array}{l}0.125 \\
0.1630 .74 \\
0.84\end{array}$ \\
\hline
\end{tabular}




\begin{tabular}{|c|c|c|c|c|c|c|c|}
\hline Parameters & $\begin{array}{l}\text { Group } 1(\mathrm{n} \\
=61)\end{array}$ & $\begin{array}{l}\text { Group } 2(\mathrm{n} \\
=50)\end{array}$ & $\begin{array}{l}\text { Group } 3 \text { (n } \\
=10)\end{array}$ & $P$-value & $\begin{array}{l}\text { Group } 1 \text { vs } \\
2\end{array}$ & $\begin{array}{l}\text { Group } 1 \text { vs } \\
3\end{array}$ & $\begin{array}{l}\text { Group } 2 \text { vs } \\
3\end{array}$ \\
\hline $\begin{array}{l}\text { Echocardiog } \\
\text { parame- } \\
\text { ters } \\
\text { LVEF (\%) } \\
\text { LVEDd } \\
\text { (mm) } \\
\text { LVESd } \\
\text { (mm) LA } \\
\text { diameter } \\
\text { (mm) } \\
\text { RVSP } \\
\text { (mmHg) } \\
\text { RV size } \\
\text { (mm) } \\
\text { TAPSE } \\
\text { (mm) RV } \\
\text { S' (cm/s) } \\
\text { Tricuspid } \\
\text { Regurgita- } \\
\text { tion Mild } \\
\text { Moderate } \\
\text { Severe } \\
\text { LVGLS } \\
\text { (-\%) } \\
\text { Reduced } \\
\text { strain } \\
\text { Diastolic } \\
\text { dysfunc- } \\
\text { tion Grade } \\
\text { I Grade II } \\
\text { Grade III }\end{array}$ & $\begin{array}{l}\text { aphic } 7.9 \\
47.8 \pm 7.2 \\
26.4 \pm 5.7 \\
26.7 \pm 4.8 \\
22 \pm 0.01 \\
30.7 \pm 3.5 \\
21.9 \pm 3.4 \\
12.3 \pm 2.3 \\
10(16.4 \%) \\
9(14.7 \%) \\
1(1.6 \%) 0 \\
(0 \%)-21 \\
\pm 3.4 \% 8 \\
(13.1 \%) 20 \\
(32.8 \%) 15 \\
(24.6 \%) 4 \\
(6.5 \%) 1 \\
(1.6 \%)\end{array}$ & $\begin{array}{l}60.3 \pm 4.3 \\
46.1 \pm 9.6 \\
25.5 \pm 7.1 \\
27.3 \pm 5.4 \\
26.1 \pm \\
13.130 .6 \\
\pm 1.921 .4 \\
\pm 2.312 .2 \\
\pm 2.913 \\
(26 \%) 12 \\
(24 \%) 0 \\
(0 \%) 1 \\
(2 \%)-18.1 \\
\pm 6.9 \% 22 \\
(44 \%) 16 \\
(32 \%) 15 \\
(30 \%) 1 \\
(2 \%) 0 \\
(0 \%)\end{array}$ & $\begin{array}{l}59.8 \pm 4.4 \\
48.7 \pm 2.1 \\
25.9 \pm 2.2 \\
24.1 \pm 7.5 \\
26.3 \pm \\
14.533 .1 \\
\pm 4.120 .3 \\
\pm 1.912 .5 \\
\pm 2.94 \\
(40 \%) 4 \\
(40 \%) 0 \\
(0 \%) 0 \\
(0 \%)-15.5 \\
\pm 3.1 \% 9 \\
(90 \%) 2 \\
(20 \%) 2 \\
(20 \%) 0 \\
(0 \%) 0 \\
(0 \%)\end{array}$ & $\begin{array}{ll}0.05 & 0.49 \\
0.37 & 0.30 \\
0.91 & 0.08 \\
0.38 & 0.88 \\
0.39 \\
<\mathbf{0 . 0 0 0 1} \\
<\mathbf{0 . 0 0 0 1} \\
0.74\end{array}$ & $\begin{array}{ll}0.08 & 0.58 \\
0.76 & 0.97 \\
0.99 & 0.97 \\
0.69 & 0.99 \\
\mathbf{0 . 0 0 4}\end{array}$ & $\begin{array}{lll}\mathbf{0 . 0 4} & 0.93 \\
0.96 & 0.32 \\
0.91 & 0.07 \\
0.28 & 0.96 \\
<\mathbf{0 . 0 0 0 1}\end{array}$ & $\begin{array}{ll}0.86 & 0.62 \\
0.98 & 0.20 \\
0.91 & 0.06 \\
0.54 & 0.93 \\
\mathbf{0 . 0 2 2}\end{array}$ \\
\hline
\end{tabular}

Abbreviations: CRP - C reactive protein; IL - interleukin; LA - left atrium; LDH - lactate dehydrogenase; LVEDd - left ventricle end diastolic dimension; LVEF - left ventricle ejection fraction; LVESd - left ventricle end systolic dimension; LVGLS - left ventricle global longitudinal strain; RV - right ventricle; RV S' - right ventricle tricuspid annulus systolic velocity; RVSP - right ventricle systolic pressure; TAPSE - tricuspid annular plane systolic excursion; TLC - total leukocyte count.

Table 3: Comparison of demographic, biochemical and echocardiographic parameters in subjects with and without reduced LVGLS

\begin{tabular}{llll}
\hline Parameters & $\begin{array}{l}\text { Group 1 (Normal } \\
\text { LVGLS) }(\mathbf{n = 9 4 )}\end{array}$ & $\begin{array}{l}\text { Group 2 (Reduced } \\
\text { LVGLS) }(\mathbf{n}=\mathbf{4 0})\end{array}$ & P-value \\
\hline Age & $52.2 \pm 11.9$ & $48.7 \pm 13.2$ & 0.13 \\
Sex (Male) & $54(57.4 \%)$ & $31(77.5 \%)$ & $\mathbf{0 . 0 3}$ \\
Comorbidities & $15(15.9 \%) 28(29.7 \%)$ & $8(20 \%) 9(22.5 \%) 1$ & 0.570 .390 .62 \\
Diabetes mellitus & $4(4.2 \%)$ & $(2.5 \%)$ & \\
Hypertension Smoking & & &
\end{tabular}




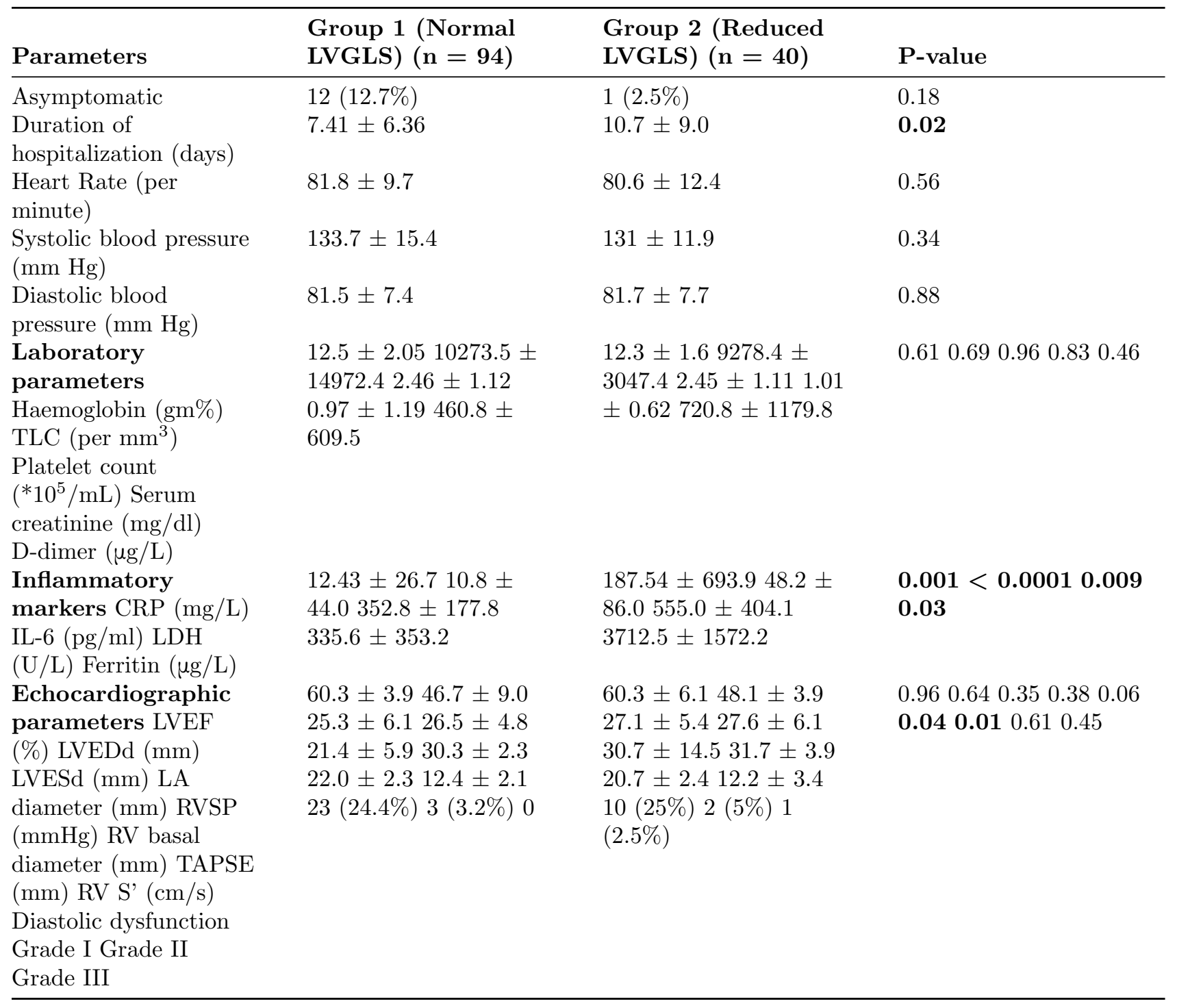

Abbreviations: CRP - C reactive protein; IL - interleukin; LA - left atrium; LDH - lactate dehydrogenase; LVEDd - left ventricle end diastolic dimension; LVEF - left ventricle ejection fraction; LVESd - left ventricle end systolic dimension; LVGLS - left ventricle global longitudinal strain; RV - right ventricle; RV S' - right ventricle tricuspid annulus systolic velocity; RVSP - right ventricle systolic pressure; TAPSE - tricuspid annular plane systolic excursion; TLC - total leukocyte count;

Figure Legends:

Figure 1: Central illustration of strain analysis of 134 COVID-19 recovered subjects.

Figure 2: Bull's eye plot of left ventricular global longitudinal strain (LVGLS) values of subjects recovered from mild (Fig 2A), moderate (Fig 2B) and severe (Fig 2C) COVID-19 illness.

Figure 3: Scatter plot graph demonstrating the correlation between LVGLS and (Fig 3a) interleukin-6 (IL6), (Fig 3b) C-reactive protein (CRP), (Fig 3c) lactate dehydrogenase (LDH) and (Fig 3d) serum ferritin.

Figure 4: Forest plot showing the predictors of reduced LVGLS in multivariate logistic regression analysis. 


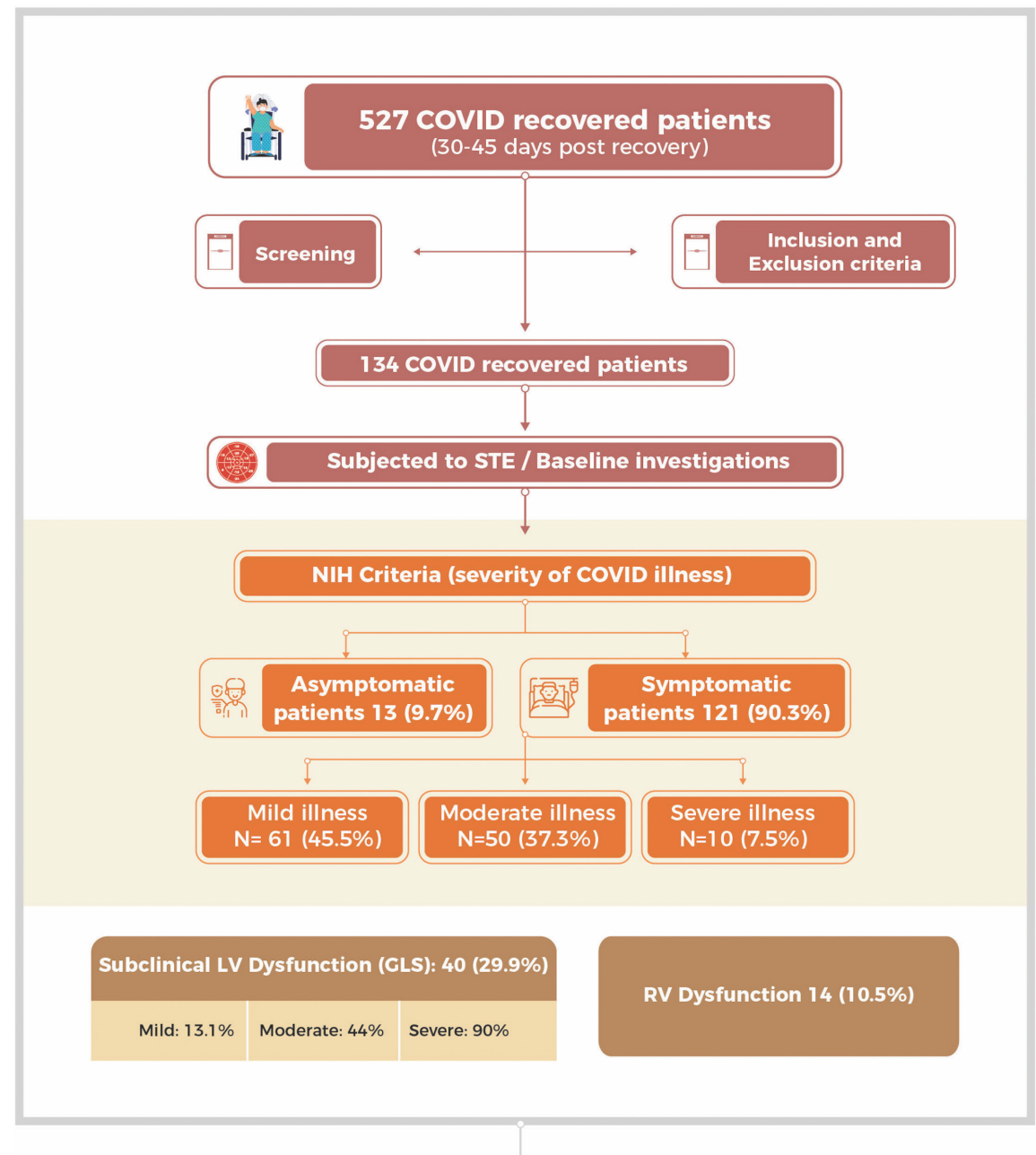

Clinical Implication

Long Term Follow up : To See Progression and Clinical Consequences of Subclinical LV Dysfunction in CovID Recovered Patients

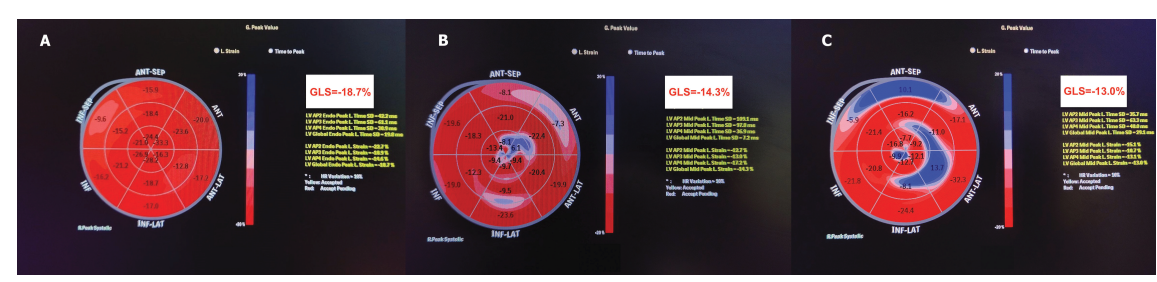


A

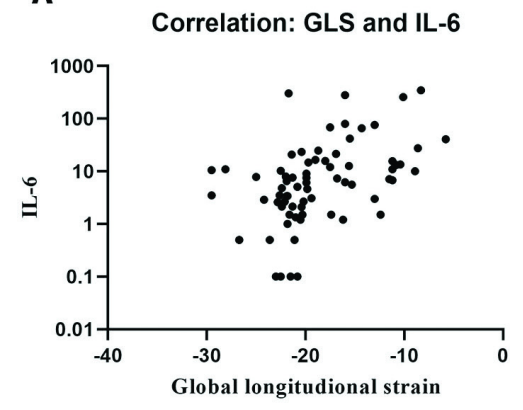

C

Correlation: GLS and Serum LDH levels

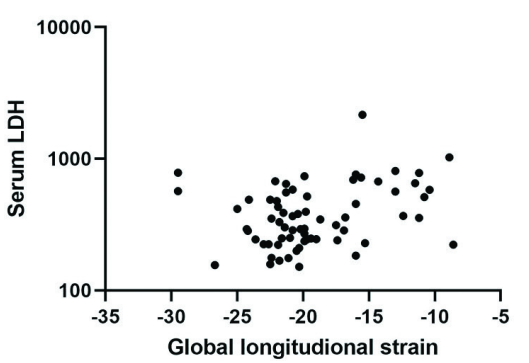

\section{B}

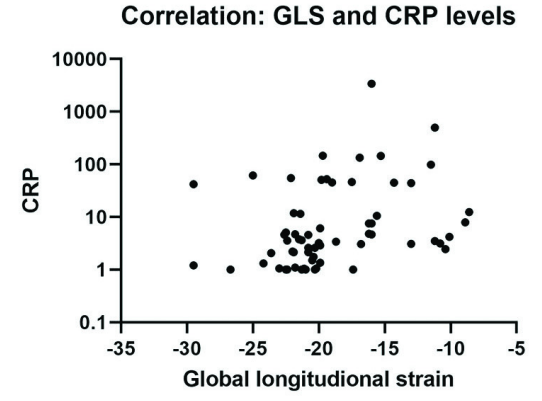

D

Correlation: GLS and Serum Ferritin levels

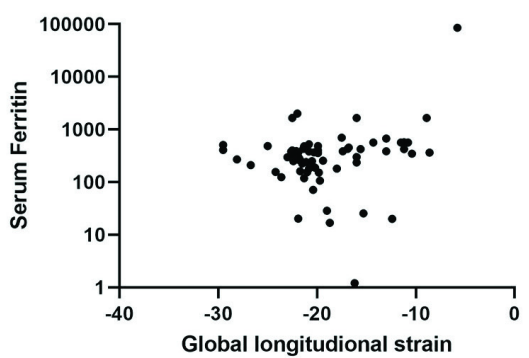

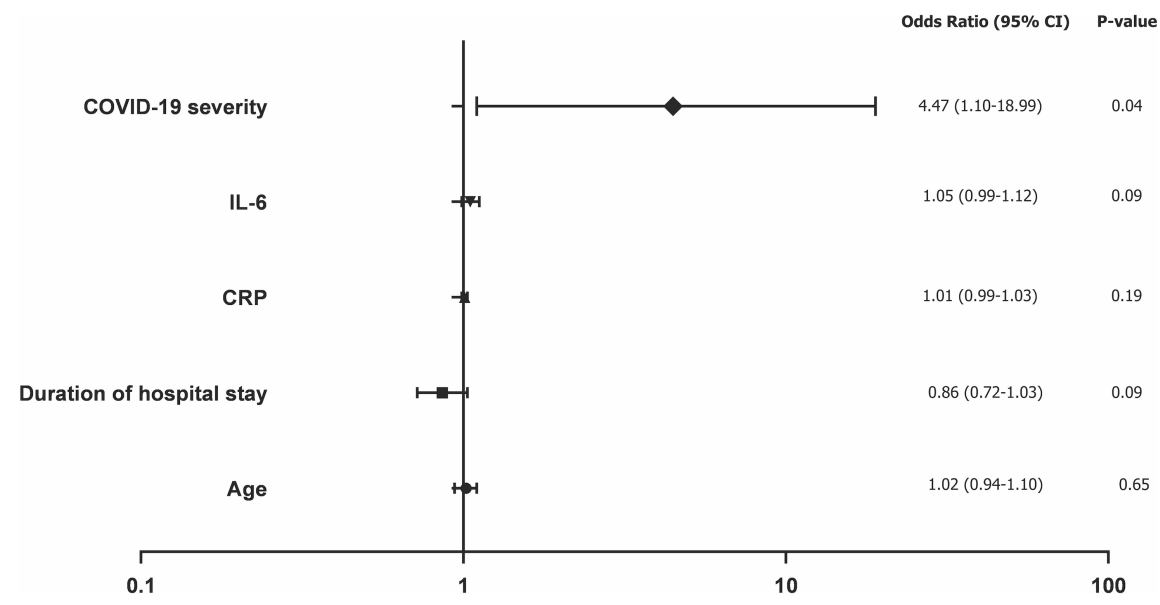

